\title{
Quality Model and Artificial Intelligence Base Fuel Ratio Management with Applications to Automotive Engine
}

\author{
Mojdeh Piran \\ Industrial Electrical and Electronic Engineering SanatkadeheSabze Pasargad. CO (S.S.P. Co), Shiraz, Iran \\ E-mail:SSP.ROBOTIC@yahoo.com
}

Farzin Piltan

Senior Researcher at Research and Development Unit, SanatkadeheSabze Pasargad Company, (S.S.P. Co), Shiraz, Iran E-mail: Piltan_f@iranssp.com; WWW.IRANSSP.COM

Mehdi Akbari

Industrial Electrical and Electronic Engineering SanatkadeheSabze Pasargad. CO (S.S.P. Co), Shiraz, Iran E-mail: SSP.ROBOTIC@yahoo.com

\author{
Mansour Bazregar \\ Industrial Electrical and Electronic Engineering SanatkadeheSabze Pasargad. CO (S.S.P. Co), Shiraz, Iran \\ E-mail: SSP.ROBOTIC@yahoo.com
}

\begin{abstract}
In this research, manage the Internal Combustion (IC) engine modeling and a multi-inputmulti-output artificial intelligence baseline chattering free sliding mode methodology scheme is developed with guaranteed stability to simultaneously control fuel ratios to desired levels under various air flow disturbances by regulating the mass flow rates of engine PFI and DI injection systems. Modeling of an entire IC engine is a very important and complicated process because engines are nonlinear, multi inputs-multi outputs and time variant. One purpose of accurate modeling is to save development costs of real engines and minimizing the risks of damag ing an engine when validating controller designs. Nevertheless, developing a small model, for specific controller design purposes, can be done and then validated on a larger, more complicated model. Analytical dynamic nonlinear modeling of internal combustion engine is carried out using elegant Euler-Lagrange method compromising accuracy and complexity. A baseline estimator with varying parameter gain is designed with guaranteed stability to allow implementation of the proposed state feedback sliding mode methodology into a MATLAB simulation environment, where the sliding mode strategy is implemented into a model engine control module ("software"). To estimate the dynamic model of IC engine fuzzy inference engine is applied to baseline sliding mode methodology. The fuzzy inference baseline sliding methodology performance was compared with a well-tuned baseline multi-loop PID controller through MATLAB simulations and showed improvements, where MATLAB simulations were
\end{abstract}

conducted to validate the feasibility of utilizing the developed controller and state estimator for automotive engines. The proposed tracking method is designed to optimally track the desired FR by minimizing the error between the trapped in-cylinder mass and the product of the desired FR and fuel mass over a given time interval.

Index Terms - IC Engine Modeling, Nonlinear Methodology To Control, Chattering Free Baseline Sliding Mode Methodology, Artificial Intelligence, Sliding Mode Methodology, Baseline Methodology, Fuzzy Inference Engine

\section{Introduction}

Internal combustion engine: Modeling of an entire internal combustion (IC) engine is a very important and complicated process because internal combustion engines are nonlinear, multi inputs-multi outputs (MIMO) and time variant. There have been several engine controller designs over the previous years in which the main goal is to improve the efficiency and exhaust emissions of the automotive engine [1-4]. Specific applications of air to fuel (A/F) ratio control based on observer measurements in the intake manifold were developed by Benninger in 1991 [5]. Another approach was to base the observer on measurements of exhaust gases measured by the oxygen sensor and on the throttle position, which was researched by Onder [6] These observer ideas used linear observer theory. 
Hedrick also used the measurements of the oxygen sensor to develop a nonlinear, sliding mode approach to control the A/F ratio [7]. All of the previous control strategies were applied to engines that used only port fuel injections, where fuel was injected in the intake manifold. Current production $\mathrm{A} / \mathrm{F}$ ratio controllers use closed loop feedback and feed forward control to achieve the desired stoichio metric mixture. These controllers use measurements from the oxygen sensor to control the desired amount of fuel that should be injected over the next engine cycle and have been able to control the A/F very well [8-9].

Quality Modeling of IC engine: In developing a valid engine model, the concept of the combustion process, abnormal combustion, and cylinder pressure must be understood. The combustion process is relatively simple and it begins with fuel and air being mixed together in the intake man ifold and cylinder. This air-fuel mixture is trapped inside cylinder after the intake valve(s) is closed and then gets compressed [14]. When the air-fuel mixture is compressed it causes the pressure and temperature to increase inside the cylinder. Unlike normal combustion, the cylinder pressure and temperature can rise so rapid ly that it can spontaneously ignite the air-fuel mixture causing high frequency cylinder pressure oscillations. These oscillations cause the metal cylinders to produce sharp noises called knock, which it caused to abnormal combustion. The pressure in the cylinder is a very important physical parameter that can be analyzed from the combustion process. After the flame is developed, the cylinder pressure steadily rises, reaches a maximum point after TDC, and finally decreases during the expansion stroke when the cylinder volume increases. Since cylinder pressure is very important to the combustion event and the engine cycle in spark ignition engines, the development of a model that produces the cylinder pressure for each crank angle degree is necessary.

Result Management based on Nonlinear Controller Methodology to FR Adjust: A nonlinear robust controller design is major subject in this work. Controller is a device which can sense information from linear or nonlinear system to improve the systems performance [10-13]. The main targets in designing control systems are stability, good disturbance rejection, and small tracking error[14-20]. Several IC engines are controlled by linear methodologies (e.g., ProportionalDerivative (PD) controller, Proportional- Integral (PI) controller or Proportional- Integral-Derivative (PID) controller), but in uncertain dynamic models this technique has limitations [21-45].

Result Management Based on Sliding Mode Methodology: Sliding mode methodology (SMM) is a significant nonlinear optimal control fuel ratio methodology under condition of partly uncertain dynamic parameters of system. This controller is used to control of highly nonlinear systems, because this type of optimal method is a robust and stable [46-69]. Conversely, pure sliding mode controller is used in many applications; it has two important drawbacks namely; chattering phenomenon, and nonlinear equivalent dynamic formulation in uncertain dynamic parameter [31-50]. It is possible to solve this problem by combining sliding mode controller and baseline law which this method can helps improve the system's tracking performance by adjusting controller's coefficient [51-55].

Result management based on Artificial Intelligence: In recent years, artificial intelligence theory has been used in nonlinear systems. Neural network, fuzzy logic and neuro-fuzzy are synergically combined with nonlinear methodology and used in nonlinear, time variant and uncertain plant (e.g., IC engine). Fuzzy logic controller (FLC) is one of the most important applications of fuzzy logic theory. This controller can be used to control nonlinear, uncertain, and noisy systems. This method is free of some model techniques as in model-based controllers. As mentioned that fuzzy logic application is not only limited to the modelling of nonlinear systems [31-36] but also this method can help engineers to design a model-free controller. The main reasons to use fuzzy logic methodology are able to give approximate recommended solution for uncertain and also certain complicated systems to easy understanding and flexible. Fuzzy logic provides a method to design a model-free controller for nonlinear plant with a set of IF-THEN rules [32-69]. The applications of artificial intelligence such as neural networks and fuzzy logic in modelling and control are significantly growing especially in recent years.

Objectives: based on previous research IC engine is MIMO, nonlinear and time variant system. One of the most active research areas in field of internal combustion engine (IC engine) is the identification, mathematical modeling and control of the internal combustion engine. Since plant modeling, as accurate as possible, is the fundamental part of any model based control approach, the system is modeled using analytical mathematical method. Sliding mode methodology is one of the robust and stable methods to tune the fuel ratio in IC engine. This method is tuned based on sliding surface slope, to adjust this parameter; based-line methodology is applied to sliding mode method. Artificial intelligence is used to estimate the dynamic model of IC engine. Proposed method is caused to reduce or eliminate the chattering as well as trajectory tracking fuel ratio in switching sliding mode highly stable method. 
This paper is organized as follows; second part focuses on the modeling dynamic formulation based on Lagrange methodology, fuzzy logic methodology and sliding mode controller to have a robust control. Third part is focused on the methodology which can be used to reduce the error, increase the performance quality and increase the robustness and stability. Simulation result and discussion is illustrated in forth part which based on trajectory following and disturbance rejection. The last part focuses on the conclusion and compare between this method and the other ones.

\section{Theorem}

Mathematical Modeling of IC Engine Using Euler Lagrange: In developing a valid engine model, the concept of the combustion process, abnormal combustion and cylinder pressure must be understood. The combustion process is relatively simple and it begins with fuel and air being mixed together in the intake manifold and cylinder. This air-fuel mixture is trapped inside cylinder after the intake valve(s) is closed and then gets compressed [6-9]. When the airfuel mixture is compressed it causes the pressure and temperature to increase inside the cylinder. In abnormal combustion, the cylinder pressure and temperature can rise so rapidly that it can spontaneously ignite the airfuel mixture causing high frequency cylinder pressure oscillations. These oscillations cause the metal cylinders to produce sharp noises called knock, which it caused to abnormal combustion. The pressure in the cylinder is a very important physical parameter that can be analyzed from the combustion process. Since cylinder pressure is very important to the combustion event and the engine cycle in spark ignition engines, the development of a model that produces the cylinder pressure for each crank angle degree is necessary.

The dynamic equations of IC engine can be written as:

$$
\begin{aligned}
& {\left[\begin{array}{c}
P F I \\
D I
\end{array}\right]=\left[\begin{array}{ll}
\dot{M}_{a i r_{11}} & \dot{M}_{\text {air } 12} \\
\dot{M}_{\text {air } 21} & \dot{M}_{\text {air } 22}
\end{array}\right]\left[\begin{array}{c}
\ddot{F R} \\
\ddot{\alpha}_{I}
\end{array}\right]+} \\
& {\left[\begin{array}{l}
P_{\text {motor }_{1}} \\
P_{\text {motor }}
\end{array}\right]\left[\begin{array}{ll}
F R & \dot{\alpha}_{I}
\end{array}\right]+\left[\begin{array}{ll}
N_{11} & N_{12} \\
N_{21} & N_{22}
\end{array}\right] \times} \\
& {\left[\begin{array}{c}
\dot{F R} \\
\dot{\alpha_{I}}
\end{array}\right]^{2}+\left[\begin{array}{c}
M_{a_{1}} \\
M_{a_{2}}
\end{array}\right]}
\end{aligned}
$$

There for to calculate the fuel ratio and equivalence ratio we can write:

$$
\begin{aligned}
& {\left[\begin{array}{c}
F \ddot{R}_{a} \\
\ddot{\alpha}_{I_{a}}
\end{array}\right]=\left[\begin{array}{ll}
\dot{M}_{\text {air } 11} & \dot{M}_{\text {air } 12} \\
\dot{M}_{\text {air } 21} & \dot{M}_{\text {air } 22}
\end{array}\right]^{-1}\left\{\left[\begin{array}{c}
P F I \\
D I
\end{array}\right]-\right.} \\
& \left\{\left[\begin{array}{l}
P_{\text {motor }_{1}} \\
P_{\text {motor }_{2}}
\end{array}\right]\left[\begin{array}{ll}
F R & \dot{\alpha}_{I_{a}}
\end{array}\right]+\left[\begin{array}{ll}
N_{11} & N_{12} \\
N_{21} & N_{22}
\end{array}\right] \times\right.
\end{aligned}
$$

$$
\left.\left.\left[\begin{array}{c}
F \dot{R}_{a} \\
\alpha_{I_{a}}
\end{array}\right]^{2}+\left[\begin{array}{c}
M_{a_{1}} \\
M_{a_{2}}
\end{array}\right]\right\}\right\}
$$

To solve $\dot{\boldsymbol{M}}_{\boldsymbol{a i r}}$, we can write;

$$
\dot{M}_{a i r}=\left[\begin{array}{ll}
\dot{M}_{\text {air } 11} & \dot{M}_{\text {air 12 }} \\
\dot{M}_{\text {air } 21} & \dot{M}_{\text {air 22 }}
\end{array}\right]
$$$$
\text { Where } \dot{M}_{\text {air } 12}=\dot{M}_{\text {air }} 21
$$

Where $\dot{\boldsymbol{M}}_{\text {air }}$ is the ratio of the mass of air.

Matrix $P_{\text {motor }}$ is a $1 \times 2$ matrix:

$$
P_{\text {motor }}=\left[\begin{array}{l}
\boldsymbol{P}_{1} \\
\boldsymbol{P}_{2}
\end{array}\right]
$$

Matrix engine angular speed matrix $(N)$ is a $2 \times$ 2 matrix

$$
N=\left[\begin{array}{ll}
N_{11} & N_{12} \\
N_{21} & N_{22}
\end{array}\right]
$$

Where, Matrix mass of air in cy linder for combustion matrix $\left(M_{a}\right)$ is a $1 \times 2$ matrix.

$$
M_{a}=\left[\begin{array}{l}
M_{a_{1}} \\
M_{a_{2}}
\end{array}\right]
$$

The above target equivalence ratio calculation will be combined with fuel ratio calculation that will be used for controller design purpose.

Sliding Mode methodology: Consider a nonlinear single input dynamic system is defined by [10-17]:

$$
x^{(n)}=f(\vec{x})+b(\vec{x}) u
$$

Where $\mathrm{u}$ is the vector of control input, $\boldsymbol{x}^{(\boldsymbol{n})}$ is the $\boldsymbol{n}^{\text {th }}$ derivation of $x, x=\left[x, \dot{x}, \ddot{x}, \ldots, x^{(n-1)}\right]^{T}$ is the state vector, $\boldsymbol{f}(\boldsymbol{x})$ is unknown or uncertainty, and $\boldsymbol{b}(\boldsymbol{x})$ is of known sign function. The main goal to design this controller is train to the desired state; $\boldsymbol{x}_{\boldsymbol{d}}=$ $\left[x_{d}, \dot{x}_{d}, \ddot{x}_{d}, \ldots, x_{d}{ }^{(n-1)}\right]^{T}$, and trucking error vector is defined by [18-30]:

$$
\widetilde{x}=x-x_{d}=\left[\widetilde{x}, \ldots, \widetilde{x}^{(n-1)}\right]^{T}
$$

A time-varying sliding surface $\boldsymbol{s}(\boldsymbol{x}, \boldsymbol{t})$ in the state space $\boldsymbol{R}^{\boldsymbol{n}}$ is given by [31-45]:

$$
s(x, t)=\left(\frac{d}{d t}+\lambda\right)^{n-1} \tilde{x}=0
$$


where $\lambda$ is the positive constant. To further penalize tracking error, integral part can be used in sliding surface part as follows [10]:

$$
s(x, t)=\left(\frac{d}{d t}+\lambda\right)^{n-1}\left(\int_{0}^{t} \tilde{x} d t\right)=0
$$

The main target in this methodology is kept the sliding surface slope $s(x, t)$ near to the zero. Therefore, one of the common strategies is to find input $\boldsymbol{U}$ outside of $\boldsymbol{s}(\boldsymbol{x}, \boldsymbol{t})[10]$.

$$
\frac{1}{2} \frac{d}{d t} s^{2}(x, t) \leq-\zeta|s(x, t)|
$$

where $\zeta$ is positive constant.

$$
\text { If } \mathbf{S}(\mathbf{0})>\mathbf{0} \rightarrow \frac{\mathrm{d}}{\mathrm{dt}} \mathbf{S}(\mathbf{t}) \leq-\zeta
$$

To eliminate the derivative term, it is used an integral term from $\mathrm{t}=0$ to $\mathrm{t}=\boldsymbol{t}_{\text {reach }}$

$$
\begin{aligned}
& \int_{t=0}^{t=t_{\text {reach }}} \frac{d}{d t} S(t) \leq-\int_{t=0}^{t=t_{\text {reach }}} \eta \rightarrow \\
& S\left(t_{\text {reach }}\right)^{-S(0)} \leq-\zeta\left(t_{\text {reach }}-0\right)
\end{aligned}
$$

Where $t_{\text {reach }}$ is the time that trajectories reach to the sliding surface so, suppose $\mathrm{S}\left(t_{\text {reach }}=0\right)$ defined as

$$
0-S(0) \leq-\eta\left(t_{\text {reach }}\right) \rightarrow t_{\text {reach }} \leq \frac{S(0)}{\zeta}
$$

And

$$
\begin{aligned}
& \text { if } S(0)<0 \rightarrow 0-S(0) \leq-\eta\left(t_{\text {reach }}\right) \rightarrow \\
& S(0) \leq-\zeta\left(t_{\text {reach }}\right) \rightarrow t_{\text {reach }} \leq \frac{|S(0)|}{\eta}
\end{aligned}
$$

Equation (15) guarantees time to reach the sliding surface is smaller than $\frac{|\boldsymbol{S}(\mathbf{0})|}{\zeta}$ since the trajectories are outside of $S(t)$.

$$
\text { if } S_{t_{\text {reach }}}=S(0) \rightarrow \operatorname{error}\left(x-x_{d}\right)=0
$$

suppose $\mathrm{S}$ is defined as

$$
\begin{aligned}
& s(x, t)=\left(\frac{d}{d t}+\lambda\right) \quad \tilde{x}=\left(\dot{\mathbf{x}}-\dot{\mathbf{x}}_{\mathrm{d}}\right)+ \\
& \lambda\left(\mathbf{x}-\mathbf{x}_{\mathrm{d}}\right)
\end{aligned}
$$

The derivation of $\mathrm{S}$, namely, $\dot{S}$ can be calculated as the following;

$$
\dot{S}=\left(\ddot{\mathbf{x}}-\ddot{\mathbf{x}}_{\mathbf{d}}\right)+\lambda\left(\dot{\mathbf{x}}-\dot{\mathbf{x}}_{\mathbf{d}}\right)
$$

suppose the second order systemis defined as;

$$
\begin{aligned}
& \ddot{x}=f+u \\
& \lambda\left(\dot{\mathbf{x}}-\dot{\mathbf{x}}_{d}\right)
\end{aligned} \rightarrow \dot{S}=f+U-\ddot{x}_{d}+
$$

Where $\boldsymbol{f}$ is the dynamic uncertain, and also since $S=0$ and $\dot{S}=0$, to have the best approximation , $\widehat{\boldsymbol{U}}$ is defined as

$$
\widehat{U}=-\widehat{f}+\ddot{x}_{d}-\lambda\left(\dot{\mathbf{x}}-\dot{\mathbf{x}}_{\mathbf{d}}\right)
$$

A simple solution to get the sliding condition when the dynamic parameters have uncertainty is the switching control law:

$$
U_{d i s}=\widehat{U}-K(\vec{x}, t) \cdot \operatorname{sgn}(s)
$$

where the switching function $\operatorname{sgn}(\mathbf{S})$ is defined as $[11,16]$

$$
\operatorname{sgn}(s)= \begin{cases}1 & s>0 \\ -1 & s<0 \\ 0 & s=0\end{cases}
$$

and the $\boldsymbol{K}(\overrightarrow{\boldsymbol{x}}, \boldsymbol{t})$ is the positive constant. Suppose by (11) the following equation can be written as,

$$
\begin{aligned}
& \frac{1}{2} \frac{d}{d t} S^{2}(x, t)=S \cdot S=[f-\widehat{f}-K \operatorname{sgn}(s)] \\
& S=(f-\widehat{f}) \cdot S-K|S|
\end{aligned}
$$

and if the equation (15) instead of (14) the sliding surface can be calculated as

$$
\begin{aligned}
& s(x, t)=\left(\frac{d}{d t}+\lambda\right)^{2}\left(\int_{0}^{t} \tilde{x} d t\right)=\left(\dot{x}-\dot{\mathbf{x}}_{\mathrm{d}}\right)+ \\
& 2 \lambda\left(\dot{\mathrm{x}}-\dot{\mathbf{x}}_{\mathrm{d}}\right)-\lambda^{2}\left(\mathrm{x}-\mathbf{x}_{\mathrm{d}}\right)
\end{aligned}
$$

in this method the approximation of $\boldsymbol{U}$ is computed as [26]

$$
\widehat{U}=-\widehat{f}+\ddot{x}_{d}-2 \lambda\left(\dot{\mathbf{x}}-\dot{\mathbf{x}}_{\mathbf{d}}\right)+\lambda^{2}\left(\mathbf{x}-\mathbf{x}_{\mathbf{d}}\right)
$$

Baseline methodology: The design of a baseline controller to control the fuel ratio was very straight forward. Since there was an output from the fuel ratio model, this means that there would be two inputs into the baseline controller. Similarly, the output of the controller result from the two control inputs of the port fuel injector signal and direct injector signal. In a typical PID controller, the controller corrects the error between the desired output value and the measured value. Since the equivalence ratio and fuel ratio are the two measured signals, two controllers were cascaded together to control the PFI and DI inputs. The first was a PID controller that corrected the error between the desired equivalence ratio and the measured equivalence ratio; while the second was only a proportional integral (PI) controller that corrected the fuel ratio error.

$$
e_{1}(t)=\alpha_{\text {target }}(t)-\alpha_{d}(t)
$$




$$
\begin{aligned}
& e_{2}(t)= \\
& \text { Fuel ratio }_{a}(t)-\text { Fuel Ratio }_{d}(t) \\
& P F I_{\alpha}=K_{p_{a}} e_{1}+K_{V_{a}} \dot{e}_{1}+K_{I_{a}} \sum e_{1} \\
& D I_{\alpha}=K_{p_{b}} e_{1}+K_{V_{b}} e_{1}+K_{I_{b}} \sum e_{1} \\
& P F I_{F}=\left(K_{p_{c}} e_{2}+K_{I_{c}} \sum e_{2}\right) \times P F I_{\alpha} \\
& D I_{F}=D I_{\alpha}
\end{aligned}
$$

\section{Methodol ogy}

Baseline Sliding Mode Controller Methodology: The design of a baseline controller to control the sliding surface slope was very straight forward. Since there was an output from the sliding surface slope model, this means that there would be two inputs into the baseline controller. Similarly, the output of the controller result from the control input of the sliding surface slope. In a typical PID controller, the controller corrects the error between the desired output value and the measured value. Since the sliding surface slope is the measured signal, two controllers were cascaded together to control the sliding surface slope. The first was a PID method that corrected the error between the desired FR and the measured FR; while the second was only a proportional integral (PI) method that corrected the sliding surface, error and integral of error.

$$
\begin{aligned}
& e(t)=F R_{\text {desired }}(t)-F R_{\text {actual }}(t) \\
& S_{\alpha}=\lambda_{a} e+\dot{e}+\left(\frac{\lambda_{a}}{2}\right)^{2} \sum e \\
& S_{T}=\left(\lambda_{a} e+\left(\frac{\lambda_{a}}{2}\right)^{2} \sum e\right) \times S_{\alpha} \\
& S_{T}=\left(\lambda_{a} e+\left(\frac{\lambda_{a}}{2}\right)^{2} \sum e\right) \times\left(\lambda_{a} e+\dot{e}+\right. \\
& \left.\left(\frac{\lambda_{a}}{2}\right)^{2} \sum e\right)
\end{aligned}
$$

Artificial intelligence (Fuzzy) Based Management Baseline Sliding Mode Methodology: this part is focused on design SISO fuzzy estimation baseline sliding mode methodology for system's managment based on Lyapunov formulation. The firs type of fuzzy systems is given by

$$
f(x)=\sum_{l=1}^{M} \theta^{l} \mathcal{E}^{l}(x)=\theta^{T} \mathcal{E}(x)
$$

Where

$$
\begin{aligned}
& \theta=\left(\theta^{1}, \ldots, \theta^{M}\right)^{T}, \mathcal{E}(x)= \\
& \left(\mathcal{E}^{1}(x), \ldots, \mathcal{E}^{M}(x)\right)^{T}, \text { and } \mathcal{E}^{l}(x)= \\
& : \prod_{i=1}^{n} \frac{{ }_{A_{i}^{l}}^{l}\left(x_{i}\right)}{\sum_{l=1}^{M}}\left(\prod_{i=1}^{n} \mu_{A_{i}^{l}}\left(x_{i}\right)\right) . \quad \theta^{1}, \ldots, \theta^{M} \quad \text { are }
\end{aligned}
$$
adjustable parameters in $(23) . \mu_{A_{1}^{1}}\left(x_{1}\right), \ldots, \mu_{A_{n}^{m}}\left(x_{n}\right)$ are given membership functions whose parameters will not change over time.

The second type of fuzzy systems is given by

$$
f(x)=\frac{\sum_{l=1}^{M} \theta^{l}\left[\prod_{i=1}^{n} \exp \left(-\left(\frac{x_{i}-\alpha_{i}^{l}}{\delta_{i}^{l}}\right)^{2}\right)\right]}{\sum_{l=1}^{M}\left[\prod_{i=1}^{n} \exp \left(-\left(\frac{x_{i}-\alpha_{i}^{l}}{\delta_{i}^{l}}\right)^{2}\right)\right]}
$$

Where $\theta^{l}, \alpha_{i}^{l}$ and $\delta_{i}^{l}$ are all adjustable parameters. From the universal approximation theorem, we know that we can find a fuzzy system to estimate any continuous function. For the first type of fu zzy systems, we can only adjust $\theta^{l}$ in (23). We define $f^{\wedge}(x \mid \theta)$ as the approximator of the real function $f(x)$.

$$
f^{\wedge}(x \mid \theta)=\theta^{T} \varepsilon(x)
$$

We define $\theta^{*}$ as the values for the minimum error:

$$
\theta^{*}=\arg \min _{\theta \in \Omega}\left[\sup _{x \in U}\left|f^{\wedge}(x \mid \theta)-g(x)\right|\right]
$$

Where $\Omega$ is a constraint set for $\theta$. For specific $x, \sup _{x \in U}\left|f^{\wedge}\left(x \mid \theta^{*}\right)-f(x)\right|$ is the minimum approximation error we can get.

We used the first type of fuzzy systems (23) to estimate the nonlinear system (11) the fuzzy formulation can be write as below;

$$
\begin{aligned}
f(x \mid \theta) & =\theta^{T} \varepsilon(x) \\
& =\frac{\sum_{l=1}^{n} \theta^{l}\left[\mu_{A}(x)\right]}{\sum_{l=1}^{n}\left[\mu_{A^{l}}(x)\right]}
\end{aligned}
$$

Where $\theta^{1}, \ldots, \theta^{n}$ are adjusted by an adaptation law. The adaptation law is designed to minimize the parameter errors of $\theta-\theta^{*}$. A MIMO (multi-input multi-output) fuzzy system is designed to compensate the uncertainties of the nonlinear system. The parameters of the fuzzy system are adjusted by adaptation laws. The tracking error and the sliding surface state are defined as:

$$
\begin{aligned}
& e=q-q_{d} \\
& s=\dot{e}+\lambda_{e}
\end{aligned}
$$

We define the reference state as

$$
\begin{aligned}
& \dot{\boldsymbol{q}}_{r}=\dot{\boldsymbol{q}}-\boldsymbol{s}=\dot{\boldsymbol{q}}_{d}-\lambda \boldsymbol{e} \\
& \ddot{\boldsymbol{q}}_{r}=\ddot{\boldsymbol{q}}-\dot{\boldsymbol{s}}=\ddot{\boldsymbol{q}}_{d}-\lambda \dot{e}
\end{aligned}
$$


The general MIMO if-then rules are given by

$$
\begin{aligned}
& R^{l} \text { : if } x_{1} \text { is } A_{1}^{l}, x_{2} \text { is } A_{2}^{l}, \ldots, x_{n} \text { is } A_{n}^{l} \\
& \text { then } y_{1} \text { is } B_{1}^{l}, \ldots, y_{m} \text { is } B_{m}^{l}
\end{aligned}
$$

Where $l=1,2, \ldots, M$ are fuzzy if-then rules; $x=$ $\left(x_{1}, \ldots, x_{n}\right)^{T}$ and $y=\left(y_{1}, \ldots, y_{n}\right)^{T}$ are the input and output vectors of the fuzzy system. The MIMO fuzzy systemis define as

$$
f(x)=\ominus^{T} \varepsilon(x)
$$

Where

$$
\ominus^{T}=\left(\theta_{1}, \ldots, \theta_{m}\right)^{T}=\left[\begin{array}{c}
\theta_{1}^{1}, \theta_{1}^{2}, \ldots, \theta_{1}^{M} \\
\theta_{2}^{1}, \theta_{2}^{2}, \ldots, \theta_{2}^{M} \\
\vdots \\
\theta_{m}^{1}, \theta_{m}^{2}, \ldots, \theta_{m}^{M}
\end{array}\right]
$$

$\varepsilon(x)=\left(\varepsilon^{1}(x), \ldots, \varepsilon^{M}(x)\right)^{T}, \quad \varepsilon^{1}(x)=\prod_{i=1}^{n} \mu_{A_{i}^{l}}\left(x_{i}\right) /$

$\sum_{l=1}^{M}\left(\prod_{i=1}^{n} \mu_{A_{i}^{l}}\left(x_{i}\right)\right)$, and $\mu_{A_{i}^{l}}\left(x_{i}\right)$ is defined in (40). To reduce the number of fuzzy rules, we divide the fuzzy systemin to three parts:

$$
\begin{aligned}
& F^{1}(q, \dot{q})=\ominus^{1^{T}} \varepsilon(q, \dot{q}) \\
& =\left[\theta_{1}^{1^{T}} \varepsilon(q, \dot{q}), \ldots, \theta_{m}^{1^{T}} \varepsilon(q, \dot{q})\right]^{T} \\
& F^{2}\left(q, \ddot{q}_{r}\right)=\ominus^{2^{T}} \varepsilon\left(q, \ddot{q}_{r}\right) \\
& = \\
& {\left[\theta_{1}^{2^{T}} \varepsilon\left(q, \ddot{q}_{r}\right), \ldots, \theta_{m}^{2^{T}} \varepsilon\left(q, \ddot{q}_{r}\right)\right]^{T}} \\
& F^{3}(q, \ddot{q})=\ominus^{3^{T}} \varepsilon(q, \ddot{q}) \\
& \quad=\left[\theta_{1}^{3^{T}} \varepsilon(q, \dot{q}), \ldots, \theta_{m}^{3^{T}} \varepsilon(q, \ddot{q})\right]^{T}
\end{aligned}
$$

The control input is given by

$$
\begin{aligned}
& U=\left\{\left\{\left[\begin{array}{l}
P_{\text {motor }_{1}} \\
P_{\text {motor }_{2}}
\end{array}\right]\left[\begin{array}{ll}
F R & \dot{\alpha}_{I_{a}}
\end{array}\right]+\right.\right. \\
& \left.\left.\left[\begin{array}{ll}
N_{11} & N_{12} \\
N_{21} & N_{22}
\end{array}\right] \times\left[\begin{array}{c}
F \dot{R}_{a} \\
\alpha_{I_{a}}
\end{array}\right]^{2}+\left[\begin{array}{l}
M_{a_{1}} \\
M_{a_{2}}
\end{array}\right]\right\}\right\} \\
& F^{1}(q, \dot{q})+F^{2}\left(q, \ddot{q}_{r}\right)+F^{3}(q, \ddot{q})-K_{D} s- \\
& W \operatorname{Sgn}(s)
\end{aligned}
$$

$W=\operatorname{diag}\left[W_{1}, \ldots, W_{m}\right]$ and $W_{1}, \ldots, W_{m}$ are positive constants. The adaptation law is given by

$$
\begin{aligned}
\dot{\theta}_{j}^{1} & =-\Gamma_{1 j} s_{j} \varepsilon(q, \dot{q}) \\
\dot{\theta}_{j}^{2} & =-\Gamma_{2 j} s_{j} \varepsilon\left(q, \ddot{q}_{r}\right) \\
\dot{\theta}_{j}^{3} & =-\Gamma_{3 j} s_{j} \varepsilon(q, \ddot{q})
\end{aligned}
$$

Where $j=1, \ldots, m$ and $\Gamma_{1 j}-\Gamma_{3 j}$ are positive diagonal matrices.

The Lyapunov function candidate is presented as

$$
\begin{aligned}
& V=\frac{1}{2} s^{T} M s+\frac{1}{2} \sum_{j=1}^{m} \frac{1}{\Gamma_{1 j}} \emptyset_{j}^{1^{T}} \emptyset_{j}^{1}+ \\
& \frac{1}{2} \sum_{j=1}^{m} \frac{1}{\Gamma_{2 j}} \emptyset_{j}^{2^{T}} \emptyset_{j}^{2}+\frac{1}{2} \sum_{j=1}^{m} \frac{1}{\Gamma_{3 j}} \emptyset_{j}^{13^{T}} \emptyset_{j}^{3}
\end{aligned}
$$

Where $\emptyset_{j}^{1}=\emptyset_{j}^{1^{*}}-\emptyset_{j}^{1}, \emptyset_{j}^{2}=\emptyset_{j}^{2^{*}}-\emptyset_{j}^{2}$ and $\emptyset_{j}^{3}=$ $\emptyset_{j}^{3^{*}}-\emptyset_{j}^{3}$ we define

$$
\begin{aligned}
& F\left(q, \dot{q}, \ddot{q}_{r}, \ddot{q}\right)=F^{1}(q, \dot{q})+F^{2}\left(q, \ddot{q}_{r}\right)+ \\
& F^{3}(q, \ddot{q})
\end{aligned}
$$

From (29) and (30), we get

$$
\begin{aligned}
& M(q) \ddot{q}+P_{m}(\theta)+P_{n e t}(\theta)=M^{\wedge} \ddot{q}_{r}+ \\
& P_{m}(\theta)+P_{n e t}(\theta)+F\left(q, \dot{q}, \ddot{q}_{r}, \ddot{q}\right)- \\
& K_{D} s-W \operatorname{Wgn}(s)
\end{aligned}
$$

Since $\dot{q}_{r}=\dot{q}-s$ and $\ddot{q}_{r}=\ddot{q}-\dot{s}$, we get

$$
\begin{aligned}
& \boldsymbol{M} \dot{\boldsymbol{s}}+\left(\boldsymbol{P}_{\boldsymbol{m}}(\boldsymbol{\theta})+\boldsymbol{P}_{n e t}(\boldsymbol{\theta})+\boldsymbol{K}_{D}\right) \boldsymbol{s}+ \\
& \boldsymbol{W} \boldsymbol{s g n}(\boldsymbol{s})=-\Delta \boldsymbol{F}+\boldsymbol{F}\left(\boldsymbol{q}, \dot{\boldsymbol{q}}, \ddot{\boldsymbol{q}}_{r}, \ddot{\boldsymbol{q}}\right)
\end{aligned}
$$

Then $M \dot{s}+\boldsymbol{P}_{\boldsymbol{m}}(\boldsymbol{\theta})+\boldsymbol{P}_{\text {net }}(\boldsymbol{\theta})_{S}$ can be written as

$$
\begin{aligned}
& M \dot{s}+P_{m}(\theta)+P_{n e t}(\theta) s=-\Delta F+ \\
& F\left(q, \dot{q}, \ddot{q}_{r}, \ddot{q}\right)-K_{D} s-W s g n(s)
\end{aligned}
$$

Where $\quad \Delta F=\widetilde{M} \ddot{q}_{r}+\boldsymbol{P}_{\boldsymbol{m}}(\boldsymbol{\theta})+\boldsymbol{P}_{\text {net }}(\boldsymbol{\theta}), \widetilde{M}=M-$ $M^{\wedge}, \tilde{C}_{1}=\boldsymbol{P}_{\boldsymbol{m}}(\boldsymbol{\theta})+\boldsymbol{P}_{\boldsymbol{n} e t}(\boldsymbol{\theta})-\boldsymbol{P}_{\boldsymbol{m}}(\boldsymbol{\theta})+\stackrel{\boldsymbol{P}}{n e t}(\boldsymbol{\theta})$ The derivative of $V$ is

$$
\begin{aligned}
& \dot{V}=s^{T} M \dot{s}+\frac{1}{2} s^{T} \dot{M} s+\sum_{j=1}^{m} \frac{1}{\Gamma_{1 j}} \phi_{j}^{1^{T}} \dot{\emptyset}_{j}^{1}+ \\
& \sum_{j=1}^{m} \frac{1}{\Gamma_{2 j}} \emptyset_{j}^{2^{T}} \dot{\emptyset}_{j}^{2}+\sum_{j=1}^{m} \frac{1}{\Gamma_{3 j}} \emptyset_{j}^{13^{T}} \dot{\emptyset}_{j}^{3}
\end{aligned}
$$

We know that $s^{T} M \dot{s}+\frac{1}{2} s^{T} \dot{M} s=s^{T}(M \dot{s}+$ $\left.\boldsymbol{P}_{\boldsymbol{m}}(\boldsymbol{\theta})+\boldsymbol{P}_{\text {net }}(\boldsymbol{\theta})_{s}\right)$ from (45). Then

$$
\begin{aligned}
& \dot{V}=-s^{T}\left[-K_{D} s+W s g n(s)+\Delta F-\right. \\
& \left.F\left(q, \dot{q}, \ddot{q}_{r}, \ddot{q}\right)\right]+\sum_{j=1}^{m} \frac{1}{\Gamma_{1 j}} \phi_{j}^{1^{T}} \dot{\emptyset}_{j}^{1}+ \\
& \sum_{j=1}^{m} \frac{1}{\Gamma_{2 j}} \emptyset_{j}^{2^{T}} \dot{\emptyset}_{j}^{2}+\sum_{j=1}^{m} \frac{1}{\Gamma_{3 j}} \emptyset_{j}^{13^{T}} \dot{\emptyset}_{j}^{3}
\end{aligned}
$$

We define the minimum approximation error as

$$
\begin{aligned}
& \omega= \\
& \Delta \boldsymbol{F}-\left[\boldsymbol{F}^{1}\left(\boldsymbol{q}, \dot{\boldsymbol{q}} \mid \ominus^{1^{*}}\right)+\boldsymbol{F}^{2}\left(\boldsymbol{q}, \ddot{\boldsymbol{q}}_{\boldsymbol{r}} \mid \ominus^{2^{*}}\right)+\right. \\
& \left.\boldsymbol{F}^{3}\left(\boldsymbol{q}, \ddot{\boldsymbol{q}} \mid \ominus^{3^{*}}\right)\right]
\end{aligned}
$$

We plug (49) in to (50) 


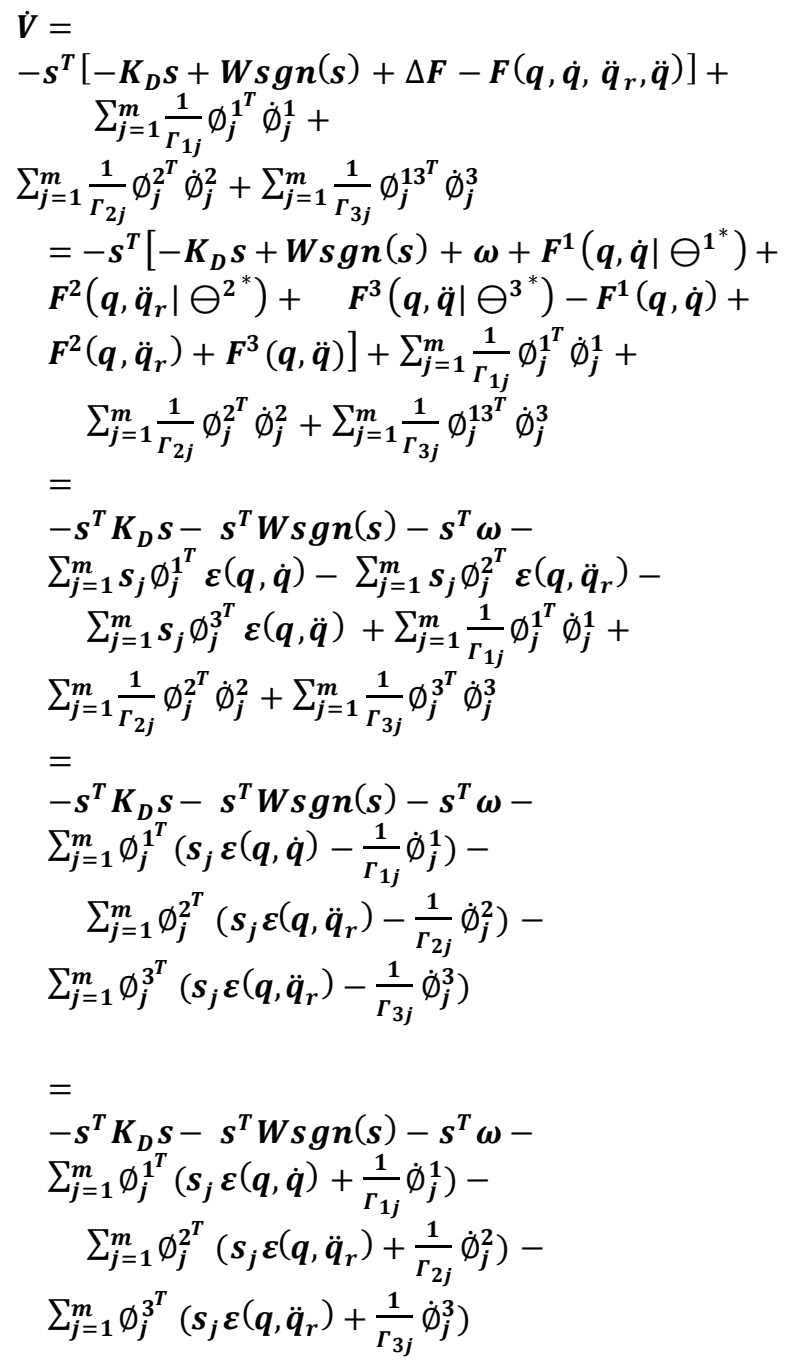

Then $\dot{V}$ becomes

$$
\begin{aligned}
\dot{V} & =-s^{T} K_{D} s-s^{T} W \operatorname{sgn}(s)-s^{T} \omega \\
& =-\sum_{j=1}^{m}\left(s_{j}^{2} K_{D j}+W_{j}\left|s_{j}\right|+s_{j} \omega_{j}\right) \\
& =-\sum_{j=1}^{m}\left[s_{j}\left(s_{j} K_{D j}+\omega_{j}\right)+W_{j}\left|s_{j}\right|\right]
\end{aligned}
$$

Since $\omega_{j}$ can be as small as possible, we can find $K_{D j}$ that $\left|s_{j}^{2} K_{D j}\right|>\left|\omega_{j}\right|\left(s_{j} \neq 0\right)$.

Therefore, we can get $s_{j}\left(s_{j} K_{D j}+\omega_{j}\right)>0$ for $s_{j} \neq 0$ and $\dot{V}<0(s \neq 0)$. Figure 3 shows the fuzzy estimator variable structure.

\section{Results and Discussion}

This section is focused on compare between baseline methodology to FR optimization (BLO) and artificial intelligence (fuzzy) baseline Slid ing Mode methodology (FBSMM). These controllers were tested by MATLAB/SIMULINK environment.

FR trackingManaging: Based on equations in sliding mode methodology; this method performance is depended on the gain updating factor $(K)$ and sliding surface slope coefficient $(\lambda)$. These two coefficients are computed by gradient descent optimization in pure SMM. After this process the main important challenge is, optimizer is depending on sliding surface slope coefficients so baseline method is apply. Figure 1 shows FR tracking performance in BLO and FBSMM without torque load disturbance.
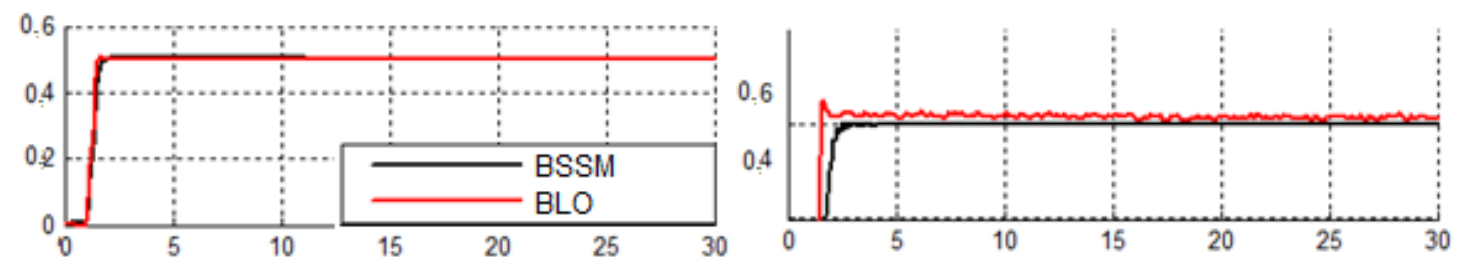

Fig. 1: FBSMM and BLO for adjust FR without torque load disturbance
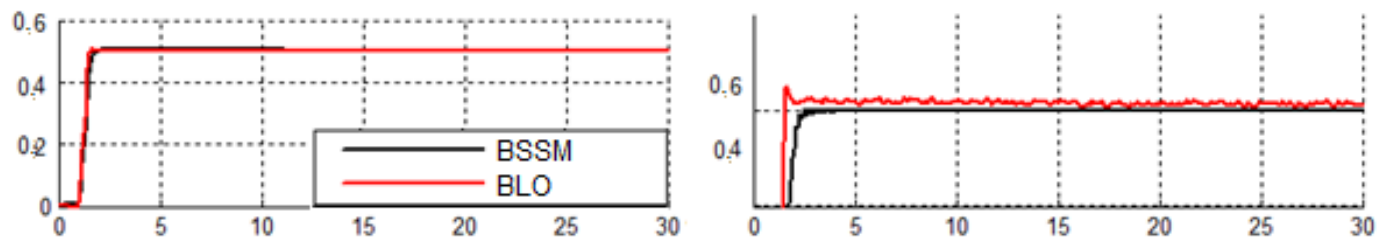

Fig. 2: FBSMM and BLO for adjust FR with $10 \%$ torque load external disturbance

Based on Figure 1 it is observed that, BLO has oscillation in this nonlinear system, caused to instability in tuning the FR but FBSMM has steady in response. BLO's overshoot is $1.3 \%$ but BSMM's overshoot is $0 \%$.
Managing the disturbance rejection: Figures 2 and 3 are show the power disturbance elimination in BLO and FBSMM with torque load disturbance. The manage disturbance rejection is used to test the robustness comparisons of these two methodologies. A variable 
limited torque load with predefined of $10 \%$ and $20 \%$ the power of input signal value is applied to this system.

Based on Figure 2; by comparing FR trajectory with $10 \%$ torque load disturbance of relative to the input signal amplitude in BSMM and BLO, BSMM's overshoot about $(0 \%)$ is lower than BLO's (2.3\%). Based on Figure 2, it is observed that FBSMM's performance is better than BLO and it also can eliminate the chattering in presence of $10 \%$ disturbance.
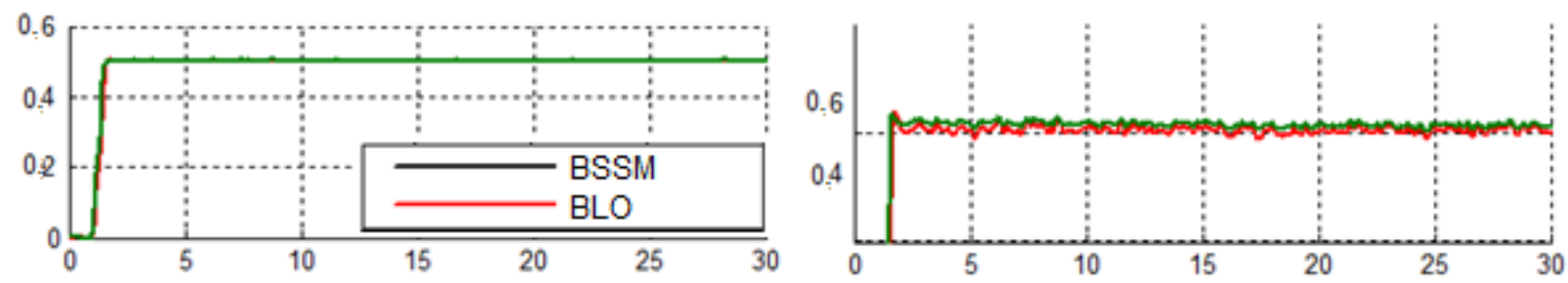

Fig. 3: FBSMM and BLO for adjust FR with $20 \%$ torque load external disturbance

Based on Figure 3; by comparing FR trajectory with $20 \%$ disturbance of relative to the input signal amplitude in FBSMM and BLO, FBSMM's overshoot about $\mathbf{( 0 . 3 2 \% )}$ ) is lower than BLO's (3.11\%). Based on Figure 3 it is observed that, these two methodologies have oscillation in presence of $20 \%$ torque load uncertainty but FBSMM is more stable and more robust than BLO.

\section{Conclusion}

Refer to this research, IC engine modeling based on Lagrange and an artificial intelligence based manage baseline sliding mode methodology is proposed for tuning the FR in internal combustion engine based on nonlinear methodology. Manage the stability and convergence of the fuzzy baseline sliding mode controller based on switching function is guarantee and proved by the LYAPUNOV method. The simulation results exhibit that the fuzzy baseline sliding mode methodology tuning the FR very well in various situations. The FBSMM gives significant steady state error managing performance when compared to BLO. The main goal in this research were modeling and manage or eliminate the chattering that proposed methodology reach to this objective by adding baseline and fuzzy method to high impact robust and stable nonlinear based methodology. The second main goal in this research was reduce dependence on sliding surface slope which baseline methodology does this objective in this research. When applied 20\% torque load disturbances in FBSMM the RMS error increased approximately $0.1 \%$ (percent of increase the BSMM RMS error $\left.=\frac{(20 \% \text { disturbance } R M S \text { error }}{\text { no disturbance } M S \text { error }}=\frac{1 e-5}{1 e-6}=0.1 \%\right)$ that in BLO the RMS error increased approximately $8 \%$ (percent of increase the BLO RMS error $\left.=\frac{(20 \% \text { disturbance } \text { RMS error }}{\text { no disturbance } R M S \text { error }}=8 \%\right)$.

\section{Acknowledgment}

The authors would like to thank the anonymous reviewers for their careful reading of this paper. This work was supported by the SSP Research and Development Corporation Program of Iran under grant no. 2012-Persian Gulf-2B.

\section{Reference}

[1] Heywood, J., "Internal Combustion Engine Fundamentals", McGraw-Hill, New York, 1988.

[2] J. G. Rivard, "Closed-loop Electronic Fuel Injection Control of the IC Engine," in Society of Automotive Engineers, 1973.

[3] J. F. Cassidy, et al, "On the Design of Electronic Automotive Engine Controls using linear Quadratic Control Theory," IEEE Trans on Control Systems, vol. AC-25, October 1980.

[4] W. E. Powers, "Applications of Optimal Control and Kalman Filtering to Automotive Systems," International Journal of Vehicle Design, vol. Applications of Control Theory in the Automotive Industry, 1983.

[5] N. F. Benninger, et al, "Requirements and Perfo mance of Engine Manage ment Systems under Transient Conditions," in Society of Automotive Engineers, 1991.

[6] C. H. Onder, et al, "Model-Based Multivariable Speed and Air-to-Fuel Ratio Control of an SI Engine," in Society of Automotive Engineers, 1993.

[7] S. B. Cho, et al, "An Observer-based Controller Design Method for Automotive Fuel-Injection Systems," in A merican Controls Conference, 1993, pp. 2567-2571. 
[8] T. Kume, et al, "Combustion Technologies for Direct Injection SI Engine," in Society of Automotive Engineers, 1996.

[9] M. Bazregar, Farzin Piltan, A. Nabaee and M.M. Ebrahimi, "Parallel Soft Computing Control Optimization Algorithm for Uncertainty Dynamic Systems", International Journal of Advanced Science and Technology, 51, 2013.

[10] Farzin Piltan, M.H. Yarmahmoudi, M. Mirzaei, S. Emamzadeh, Z. Hivand, "Design Novel Fuzzy Robust Feedback Linearization Control with Application to Robot Manipulator", International Journal of Intelligent Systems and Applications, 5(5), 2013.

[11] Sh. Tayebi Haghighi, S. Soltani, Farzin Piltan, M. kamgari, S. Zare, "Evaluation Performance of IC Engine: Linear Tunable Gain Computed Torque Controller Vs. Sliding Mode Controller", International Journal of Intelligent Systems and Applications, 5(6), 2013.

[12] Farzin Piltan, A. R. Salehi \& Nasri B Sulaiman,"Design Artificial Robust Control of Second Order System Based on Adaptive Fuzzy Gain Scheduling", World Applied Science Journal (WASJ), 13 (5): 1085-1092, 2011.

[13] Farzin Piltan, N. Sulaiman, Atefeh Gavahian, Samira Soltani \& Samaneh Roosta, "Design Mathematical Tunable Gain PID-Like Sliding Mode Fuzzy Controller with Minimum Rule Base", International Journal of Robotic and Automation, 2 (3): 146-156, 2011.

[14] Farzin Piltan , N. Sulaiman, Zahra Tajpaykar, Payman Ferdosali \& Mehdi Rashidi, "Design Artificial Nonlinear Robust Controller Based on CTLC and FSMC with Tunable Gain", International Journal of Robotic and Automation, 2 (3): 205-220, 2011.

[15] Farzin Piltan, Mohammad Mansoorzadeh, Saeed Zare, Fatemeh Shahriarzadeh, Mehdi Akbari, "Artificial tune of fuel ratio: Design a novel siso fuzzy backstepping adaptive variable structure control", International Journal of Electrical and Computer Engineering (IJECE), 3 (2): 183-204, 2013.

[16] Farzin Piltan, M. Bazregar, M. Kamgari, M. Akbari, M. Piran, "Adjust the fuel ratio by high impact chattering free sliding methodology with application to automotive engine", International Journal of Hybrid Information Technology (IJHIT), 6 (1): 13-24, 2013.

[17] Shahnaz Tayebi Haghighi, S. Soltani, Farzin Piltan, M. Kamgari, S. Zare, "Evaluation Performance of IC Engine: linear tunable gain computed torque controller Vs. Sliding mode controller", I. J. Intelligent system and application, 6 (6): 78-88, 2013.
[18] Farzin Piltan, N. Sulaiman, Payman Ferdosali \& Iraj Assadi Talooki, "Design Model Free Fuzzy Sliding Mode Control: Applied to Internal Combustion Engine", International Journal of Engineering, 5 (4):302-312, 2011.

[19] Farzin Piltan, N. Sulaiman, A. Jalali \& F. Danesh Narouei, "Design of Model Free Adaptive Fuzzy Computed Torque Controller: Applied to Nonlinear Second Order System”, International Journal of Robotics and Automation, 2 (4):245-257, 2011

[20] A. Jalali, Farzin Piltan, M. Keshtgar, M. Jalali, "Colonial Competitive Optimization Sliding Mode Controller with Application to Robot Manipulator", International Journal of Intelligent Systems and Applications, 5(7), 2013.

[21] Farzin Piltan, Amin Jalali, N. Sulaiman, Atefeh Gavahian \& Sobhan Siamak, "Novel Artificial Control of Nonlinear Uncertain System: Design a Novel Modified PSO SISO Lyapunov Based Fuzzy Sliding Mode Algorithm”, International Journal of Robotics and Automation, 2 (5): 298 316, 2011.

[22] Farzin Piltan, N. Sulaiman, Iraj Asadi Talooki \& Payman Ferdosali, "Control of IC Engine: Design a Novel MIMO Fuzzy Backstepping Adaptive Based Fuzzy Estimator Variable Structure Control", International Journal of Robotics and Automation, 2 (5):360-380, 2011.

[23] Farzin Piltan, N. Sulaiman, S.Soltani, M. H. Marhaban \& R. Ramli, "An Adaptive Sliding Surface Slope Adjustment in PD Sliding Mode Fuzzy Control For Robot Manipulator", International Journal of Control and Automation, 4 (3): 65-76, 2011.

[24] Farzin Piltan, N. Sulaiman, Mehdi Rashidi, Zahra Tajpaikar \& Payman Ferdosali, "Design and Implementation of Sliding Mode Algorithm: Applied to Robot Manipulator-A Review", International Journal of Robotics and Automation, 2 (5):265-282, 2011.

[25] Farzin Piltan, N. Sulaiman , Arash Zargari, Mohammad Keshavarz \& Ali Badri, "Design PIDLike Fuzzy Controller with Minimum Rule Base and Mathematical Proposed On-line Tunable Gain: Applied to Robot Manipulator", International Journal of Artificial Intelligence and Expert System, 2 (4):184-195, 2011.

[26] Farzin Piltan, SH. Tayebi HAGHIGHI, N. Sulaiman, Iman Nazari \& Sobhan Siamak, "Artificial Control of PUMA Robot Manipulator: A-Review of Fuzzy Inference Engine and Application to Classical Controller", International Journal of Robotics and Automation, 2 (5):401-425, 2011. 
[27] A. Salehi, Farzin Piltan, M. Mousavi, A. Khajeh, M. R. Rashidian, "Intelligent Robust Feed-forward Fuzzy Feedback Linearization Estimation of PID Control with Application to Continuum Robot", International Journal of Information Engineering and Electronic Business, 5(1), 2013.

[28] Farzin Piltan, N. Sulaiman \& I.AsadiTalooki, "Evolutionary Design on-line Sliding Fuzzy Gain Scheduling Sliding Mode Algorithm: Applied to Internal Combustion Engine", International Journal of Engineering Science and Technology, 3 (10):7301-7308, 2011.

[29] Farzin Piltan, Nasri B Su laiman, Iraj Asadi Talooki \& Payman Ferdosali, "Designing On-Line Tunable Gain Fuzzy Sliding Mode Controller Using Sliding Mode Fuzzy Algorithm: Applied to Internal Combustion Engine" World Applied Science Journal (WASJ), 15 (3): 422-428, 2011.

[30] Farzin Piltan, M.J. Rafaati, F. Khazaeni, A. Hosainpour, S. Soltani, “A Design High Impact Lyapunov Fuzzy PD-Plus-Gravity Controller with Application to Rigid Manipulator", International Journal of In formation Engineering and Electronic Business, 5(1), 2013.

[31] A. Jalali, Farzin Piltan, A. Gavahian, M. Jalali, M. Adibi, "Model-Free Adaptive Fuzzy Sliding Mode Controller Optimized by Particle Swarm for Robot man ipulator", International Journal of Information Engineering and Electronic Business, 5(1), 2013.

[32] Farzin Piltan, N. Sulaiman, Payman Ferdosali, Mehdi Rashidi \& Zahra Tajpeikar, "Adaptive MIMO Fuzzy Compensate Fuzzy Sliding Mode Algorithm: Applied to Second Order Nonlinear System", International Journal of Engineering, 5 (5): 380-398, 2011.

[33] Farzin Piltan, N. Sulaiman, Hajar Nasiri, Sadeq Allahdadi \& Mohammad A. Bairami, "Novel Robot Manipulator Adaptive Artificial Control: Design a Novel SISO Adaptive Fuzzy Sliding Algorithm Inverse Dynamic Like Method", International Journal of Engineering, 5 (5): 399 418, 2011.

[34] Farzin Piltan, N. Sulaiman, Sadeq Allahdadi, Mohammadali Dialame \& Abbas Zare, "Position Control of Robot Manipulator: Design a Novel SISO Adaptive Sliding Mode Fuzzy PD Fuzzy Sliding Mode Control", International Journal of Artificial Intelligence and Expert System, 2 (5):208-228, 2011.

[35] M. M. Ebrahimit Farzin Piltan, M. Bazregar and A.R. Nabaee "Intelligent Robust Fuzzy-Paralle1 Optimization Control of a Continuum Robot Manipulator", International Journal of Control and Automation, 6(3), 2013.

[36] Farzin Piltan, M.A. Bairami, F. Aghayari, M.R. Rashidian, "Stable Fuzzy PD Control with Parallel
Sliding Mode Compensation with Application to Rigid Manipulator", International Journal of Information Technology and Computer Science, 5(7), 2013.

[37] Farzin Piltan, N. Sulaiman, Samaneh Roosta, Atefeh Gavahian \& Samira Soltani, "Evolutionary Design of Backstepping Artificial Sliding Mode Based Position Algorithm: Applied to Robot Manipulator", International Journal of Engineering, 5 (5):419-434, 2011.

[38] Farzin Piltan, N. Sulaiman, Amin Jalali, Sobhan Siamak \& Iman Nazari, "Control of Robot Manipulator: Design a Novel Tuning MIMO Fuzzy Backstepping Adaptive Based Fuzzy Estimator Variable Structure Control”, International Journal of Control and Automation, 4 (4):91-110, 2011.

[39] Farzin Piltan, N. Sulaiman, Atefeh Gavahian, Samaneh Roosta \& Samira Soltani, "On line Tuning Premise and Consequence FIS: Design Fuzzy Adaptive Fuzzy Sliding Mode Controller Based on Lyaponuv Theory", International Journal of Robotics and Automation, 2 (5):381-400, 2011.

[40] Farzin Piltan, N. Sulaiman, Samira Soltani, Samaneh Roosta \& Atefeh Gavahian, "Artificial Chattering Free on-line Fuzzy Sliding Mode Algorithm for Uncertain System: Applied in Robot Manipulator", International Journal of Engineering, 5 (5):360-379, 2011.

[41] Farzin Piltan, F. ShahryarZadeh ,M. Mansoorzadeh ,M. kamgari, S. Zare, "Robust Fuzzy PD Method with Parallel Computed Fuel Ratio Estimation Applied to Automotive Engine "International Journal of Intelligent Systems and Applications, 5(8), 2013.

[42] Farzin Piltan, Sadeq Allahdadi, Mohammad A.Bairami \& Hajar Nasiri, "Design Auto Adjust Sliding Surface Slope: Applied to Robot Manipulator", International Journal of Robotics and Automation, 3 (1):27-44, 2011.

[43] Farzin Piltan, Mohammadali Dialame, Abbas Zare \& Ali Badri, "Design Novel Lookup Table Changed Auto Tuning FSMC:Applied to Robot Manipulator", International Journal of Engineering, 6 (1):25-41, 2012.

[44] Farzin Piltan, M. Keshavarz, A. Badri \& A. Zargari, "Design Novel Nonlinear Controller Applied to RobotManipulator: Design New Feedback Linearization Fuzzy Controller with Minimum Rule Base Tuning Method", International Journal of Robotics and Automation, 3 (1):1-12, 2012.

[45] Farzin Piltan, Mohammad A.Bairami, Farid Aghayari \& Sadeq Allahdadi, "Design Adaptive Artificial Inverse Dynamic Controller: Design Sliding Mode Fuzzy Adaptive New Inverse 
Dynamic Fuzzy Controller", International Journal of Robotics and Automation, (1):13-26, 2012.

[46] Farzin Piltan, Sadeq Allahdadi, Mohammad A.Bairami \& Hajar Nasiri, "Design Auto Adjust Sliding Surface Slope: Applied to Robot Manipulator", International Journal of Robotics and Automation, 3 (1):27-44, 2012.

[47] Farzin Piltan, F. Aghayari, M. Rashidian \& M. Shamsodini, "A New Estimate Sliding Mode Fuzzy Controller for RoboticManipulator", International Journal of Robotics and Automation, 3 (1):45-60, 2012

[48] Farzin Piltan, Iman Nazari, Sobhan Siamak, Payman Ferdosali, "Methodology of FPGA-Based Mathematical error-Based Tuning Sliding Mode Controller", International Journal of Control and Automation, 5(1), 89-118, 2012.

[49] Farzin Piltan, Bamdad Boroomand, Arman Jahed \& Hossein Rezaie, "Methodology of Mathematical Error-Based Tuning Sliding Mode Controller", International Journal of Engineering, 6 (2):96-117, 2012.

[50] Farzin Piltan, S. Emamzadeh, Z. Hivand, F. Shahriyari \& Mina Mirazaei. " PUMA-560 Robot Manipulator Position Sliding Mode Control Methods Using MATLAB/SIMULINK and Their Integration into Graduate/Undergraduate Nonlinear Control, Robotics and MATLAB Courses", International Journal of Robotics and Automation, 3(3):106-150, 2012.

[51] Farzin Piltan, A. Hosainpour, E. Mazlomian, M.Shamsodini, M.H Yarmahmoudi. "Online Tuning Chattering Free Sliding Mode Fuzzy Control Design: Lyapunov Approach", International Journal of Robotics and Automation, 3(3):77-105, 2012.

[52] Farzin Piltan, R. Bayat, F. Aghayari, B. Boroomand. "Design Error-Based Linear ModelFree Evaluation Performance Computed Torque Controller", International Journal of Robotics and Automation, 3(3):151-166, 2012.

[53] Farzin Piltan, J. Meigolinedjad, S. Mehrara, S. Rahmdel. "Evaluation Performance of 2nd Order Nonlinear System: Baseline Control Tunable Gain Sliding Mode Methodology", International Journal of Robotics and Automation, 3(3): 192-211, 2012.

[54] Farzin Piltan, Mina Mirzaei, Forouzan Shahriari, Iman Nazari, Sara Emamzadeh, "Design Baseline Computed Torque Controller", International Journal of Engineering, 6(3): 129-141, 2012.

[55] Farzin Piltan, Sajad Rahmdel, Saleh Mehrara, Reza Bayat , "Sliding Mode Methodology Vs. Computed Torque Methodology Using MATLAB/SIMULINK and Their Integration into Graduate Nonlinear Control Courses" ,
International Journal of Engineering, 6(3): 142-177, 2012.

[56] Farzin Piltan, M.H. Yarmahmoudi, M. Shamsodini, E.Mazlomian, A.Hosainpour. "PUMA-560 Robot Manipulator Position Computed Torque Control Methods Using MATLAB/SIMULINK and Their Integration into Graduate Nonlinear Control and MATLAB Courses", International Journal of Robotics and Automation, 3(3): 167-191, 2012.

[57] Farzin Piltan, Hossein Rezaie, Bamdad Boroomand, Arman Jahed. "Design Robust Backstepping on-line Tuning Feedback Linearization Control Applied to IC Engine", International Journal of Advance Science and Technology, 11:40-22, 2012.

[58] Farzin Piltan, S. Siamak, M.A. Bairami and I. Nazari." Gradient Descent Optimal Chattering Free Sliding Mode Fuzzy Control Design: Lyapunov Approach", International Journal of Advanced Science and Technology, 43: 73-90, 2012.

[59] Farzin Piltan, M.R. Rashidian, M. Shamsodini and S. Allahdadi. "Effect of Rule Base on the FuzzyBased Tuning Fuzzy Sliding Mode Controller: Applied to $2^{\text {nd }}$ Order Nonlinear System", International Journal of Advanced Science and Technology, 46:39-70, 2012.

[60] Farzin Piltan, A. Jahed, H. Rezaie and B. Boroomand." Methodology of Robust Linear Online High Speed Tuning for Stable Sliding Mode Controller: Applied to Nonlinear System", International Journal of Control and Automation, 5(3): 217-236, 2012.

[61] Farzin Piltan, R. Bayat, S. Mehara and J. Meigolinedjad. "GDO Artificial IntelligenceBased Switching PID Baseline Feedback Linearization Method: Controlled PUMA Workspace", International Journal of Information Engineering and Electronic Business, 5: 17-26, 2012.

[62] Farzin Piltan, B. Boroomand, A. Jahed and H. Rezaie. "Performance-Based Adaptive Gradient Descent Optimal Coefficient Fuzzy Sliding Mode Methodology", International Journal of Intelligent Systems and Applications, 11: 40-52 2012.

[63] Farzin Piltan, S. Mehrara, R. Bayat and S. Rahmdel. " Design New Control Methodology of Industrial Robot Manipulator: Sliding Mode Baseline Methodology", International Journal of Hybrid Information Technology, 5(4):41-54, 2012.

[64] AH Aryanfar, MR Khammar, Farzin Piltan, "Design a robust self-tuning fuzzy sliding mode control for second order systems", International Journal of Engineering Science REsearch, 3(4): 711-717, 2012. 
[65] Farzin Piltan, Shahnaz Tayebi Haghighi, "Design Gradient Descent Optimal Sliding Mode Control of Continuum Robots", International Journal of Robotics and Automation, 1(4): 175-189, 2012.

[66] Farzin Piltan, A. Nabaee, M.M. Ebrahimi, M. Bazregar, "Design Robust Fuzzy Sliding Mode Control Technique for Robot Manipulator Systems with Modeling Uncertainties", International Journal of Information Technology and Computer Science, 5(8), 2013.

[67] Farzin Piltan, M. Akbari, M. Piran , M. Bazregar. "Design Model Free Switching Gain Scheduling Baseline Controller with Application to Automotive Engine", International Journal of Information Technology and Computer Science, 01:65-73, 2013.

[68] Farzin Piltan, M. Piran , M. Bazregar, M. Akbari, "Design High Impact Fuzzy Baseline Variable Structure Methodology to Artificial Adjust Fuel Ratio", International Journal of Intelligent Systems and Applications, 02: 59-70, 2013.

[69] Farzin Piltan, M. Mansoorzadeh, M. Akbari, S. Zare, F. ShahryarZadeh "Management of Environmental Pollution by Intelligent Control of Fuel in an Internal Combustion Engine" Global Journal of Biodiversity Science And Management, 3(1), 2013.

\section{Authors' Profiles}

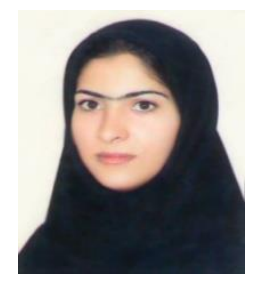

Mojdeh Piran is an industrial management researcher of research and development company SSP. Co. She is now pursuing her Master in industrial management. She is an expert Industrial and Quality Management in this company. Her research activities deal with the IC engine control, artificial intelligence and expert system.

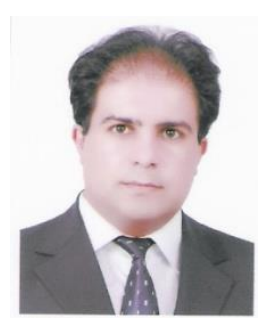

Farzin Piltan was born on 1975 , Shiraz, Iran. In 2004 he is jointed the research and development company, SSP Co, Shiraz, Iran. In addition to 7 textbooks, Farzin Piltan is the main author of more than 80 scientific papers in refereed journals. He is editorial board of international journal of control and automation (IJCA), editorial board of IAES international journal of robotics and automation, editorial board of International Journal of Reconfigurable and Embedded Systems and reviewer of (CSC) international journal of robotics and automation. His main areas of research interests are nonlinear control, artificial control system and applied to FPGA, robotics and artificial nonlinear control and IC engine modelling and control.

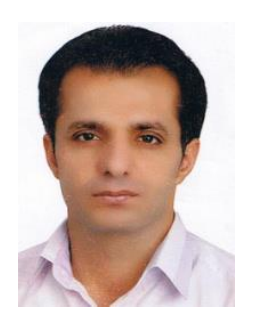

Mehdi Akbari is an industrial management researcher of research and development company SSP. Co. $\mathrm{He}$ is now pursuing his Master in industrial management. $\mathrm{He}$ is an expert Industrial and Quality Management in this company. His research activities deal with the IC engine control, artificial intelligence and supply chain management.

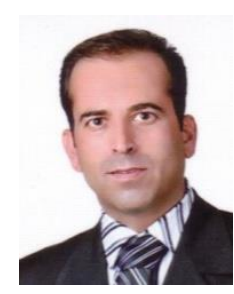

Mansour Bazregar is an industrial management researcher of research and development company SSP. Co. $\mathrm{He}$ is now pursuing his Master in industrial management. $\mathrm{He}$ is an expert Industrial and Quality Management in this company. His research activities deal with the IC engine control and supply chain management.

How to cite this paper: Mojdeh Piran, Farzin Piltan, Mehdi Akbari, Mansour Bazregar,"Quality Model and Artificial Intelligence Base Fuel Ratio Management with Applications to Automotive Engine", International Journal of Intelligent Systems and Applications(IJISA), vol.6, no.2, pp.76-87, 2014. DOI: $10.5815 /$ ijisa.2014.02.10 